\title{
Patterns of Eating and Physical Activity Attitudes and Behaviors in Relation to Body Mass Index
}

\author{
Stavroula Psouni ${ }^{1}$, Mary Hassandra ${ }^{2}$, Yannis Theodorakis ${ }^{1}$ \\ ${ }^{1}$ Department of Physical Education \& Sports Science, University of Thessaly, Trikala, Greece \\ ${ }^{2}$ Department of Sports, University of Jyvaskyla, Jyvaskyla, Finland \\ Email: stpsouni@pe.uth.gr
}

Received 2 January 2016; accepted 11 February 2016; published 14 February 2016

Copyright (C) 2016 by authors and Scientific Research Publishing Inc.

This work is licensed under the Creative Commons Attribution International License (CC BY). http://creativecommons.org/licenses/by/4.0/

(c) (i) Open Access

\section{Abstract}

The aim of the study was to identify and characterize the patterns of the psychological and behavioral characteristics, in relation to body mass index. In addition, the study examined the associations between the patterns and demographic characteristics, exercise, eating habits, and healthrelated psychological variables. Participants were 361 Greek adults, randomly selected and completed self-reported questionnaires. The surveys examined demographic characteristics, healthrelated psychological variables (attitudes and intentions toward exercise and healthy eating, perceived behavioral control, health locus of control, general health, self-control, and body image) and the behaviors of exercise and healthy eating. Cluster analysis identified two distinct profiles: the first segment was related to healthier exercise and eating behaviors, and more positive results in psychological variables. Interestingly, individuals in healthy segment correspond to a normal Body Mass Index (BMI). The second segment was related to more unhealthy behaviors, as like lower levels of exercise healthy eating and negative psychological variables. As expected, second segments' individuals had a mean overweight BMI. Furthermore, unhealthy segment profiles were related to higher psychological distress and lower self-control. Cluster analysis provides us an inspiring conclusion concerning the analysis of the combination of several variables. Healthy and unhealthy patterns were identified into two categories, using behaviors and psychological beliefs. The comparison between demographic characteristics and final clusters showed that age, education, type of sport (team or individual) and the total years of exercise appeared significant differences. All the above should be considered for the establishment of a healthy lifestyle to increase intervention effectiveness of weight-loss management.

\section{Keywords}

Healthy Eating, Physical Activity, Attitudes, BMI, Cluster Analysis 


\section{Introduction}

\subsection{Healthy Eating Habits and Exercise Significant Modifiable Behaviors for Health}

According to the World Health Organization (WHO), obesity is defined as abnormal or excessive weight that may cause serious health problems (http://www.who.int/, 2015). There are more than 1.4 billion of overweight adults and more than 40 million overweight children under the age of 5 worldwide. The definition of body mass index (BMI) as the WHO suggests that overweight adult has BMI greater than or equal to $25 \mathrm{~kg} / \mathrm{m}^{2}$, and obese adult has BMI greater than or equal to $30 \mathrm{~kg} / \mathrm{m}^{2}$. Obesity is not a simple problem, but it is a complex, multifactorial disorder, which includes dietary habits, physical activity, and behavioral and psychological factors (Bauman, Allman-Farinelli, Huxley, \& James, 2008).

Unhealthy eating is related to the development of chronic diseases, such as cardiovascular diseases, cancer, hypertension, and diabetes (Chrysochou, Askegaard, Grunert, \& Kristensen, 2010). The cause of obesity is the imbalance between the consumed calories and the expended calories (Bauman, Allman-Farinelli, Huxley, \& James, 2008). In addition, genetic factors or pathophysiological factors are also among the other reasons for obesity (Bauman, Reis, Sallis, Wells, Loos, \& Martin, 2012).

Healthy eating choices (Roefs \& Jansen, 2010) and physical activity in contrast to the sedentary lifestyle, are the principal targets of obesity prevention (Chan \& Woo, 2010). Unhealthy dietary habits and low physical activity are considered to be the main risk factors for an excessive BMI (Al-Nakeeb, Dodd, Lyons, Collins, \& Al-Nuaim, 2014). Glanz, Basil, Maibach, Goldeberg and Snyder (1998) examined eating behaviors across five measures. A healthy lifestyle, taste, nutrition, cost and weight control were essential for healthy choices. Physical activity is proved that has beneficial effects on health (Buchan, Ollis, Thomas, \& Baker, 2012). Also, it is the primary key to a successful weight loss and maintenance of BMI (Catenacci et al., 2012). People with lower BMI reported higher physical activity levels (Hallal et al., 2008). Similarly, Liao et al. (2012) found that there were significant differences in moderate-to-vigorous physical activity between normal weight and overweight men. Leisure physical activity involvement provides an effective means of health promotion, self-efficacy, and motivation (Havitz, Kaczynski, \& Mannell, 2012). Weiss, O’Loughlin, Platt, and Paradis (2007) addressed the issue of five-year predictors of physical activity, and their results showed that many variables such as age, gender, environment, and psychology affect the activity level. Besides, they observed a relationship between BMI and the risk of becoming inactive. Wagner et al. (2001) examined the effect of physical activity on BMI changes in men. Results showed that men who walked or cycled to work had lower BMI than those who did not, and they concluded that moderate-intensity physical activity for more than five years has the favorable effect on their body.

In conclusion, promotion of physical activity and healthy eating both as prevention and as treatment is essential in achieving and maintaining normal BMI and consequently better health.

To develop effective health promotion interventions is important to identify subgroups of individuals who are similar to each other regarding selected attributes (e.g., BMI), but vary significantly concerning indicators of health-related psychological characteristics.

\subsection{Health-Related Psychological Variables as Determinants for Both Behaviors}

\subsubsection{Theory of Planned Behavior for Healthy Eating and Physical Activity}

Research based on the Theory of Planned Behavior (TPB) has become very popular to explore healthy eating (Bebetsos, Chroni, \& Theodorakis, 2002; Fila \& Smith, 2006; Grønhøj, Bech-Larsen, Chan, \& Tsang, 2012) and physical activity (Chatzisarantis, Hagger, Biddle, \& Smith, 2005; Poobalan, Aucott, Clarke, \& Smith, 2012), and to understand the determinants of those behaviors. According to the theory of planned behavior (TPB), the intention is the proximal determinant of behavior whereas attitude, subjective norm, and perceived behavioral control are the determinants of intention (Ajzen, 1991).

\subsubsection{Health Locus of Control}

High scores on health locus of control are associated with healthier behaviors. In addition, literature showed associations for physical activity and healthy eating behaviors (Helmer, Krämer, \& Mikolajczyk, 2012). More specifically, higher consumption of healthy foods was found among people with higher internal locus of control scores (Bennett, Moore, Smith, Murphy, \& Smith, 1994). Previous research about relationships between health locus of control and exercise showed that higher scores on the chance dimensions were linked to fewer sports 
activity (Grotz, Hapke, Lampert, \& Baumeister, 2011) and higher internal health locus of control were related to greater responsibilities for the exercise outcomes (Doganis, Theodorakis, \& Bagiatis, 1991).

\subsubsection{Psychological Distress}

Overweight individuals have more possibilities of developing mental health difficulties (Titchener \& Wong, 2015). The relationship between BMI and mental health has shown that individuals with higher BMI are more vulnerable to developing anxiety and mood disorders in comparison with those with normal weight (Wijk, 2011; Scott, McGee, Wells, \& Oakley Browne, 2008). Depression measures were found to have the higher association with underweight and obese participants, and lower association with normal weight and overweight participants. These relationships were found to be stronger among women than men (De Wit et al., 2010). In addition, psychological variables such as body image distraction, social-emotional dysfunction, and depression were found to be associated with a BMI more than $40 \mathrm{~kg} / \mathrm{m}^{2}$ (Brandheim, Rantakeisu, \& Starrin, 2013). Adolescents and young adults with higher BMI had the higher level of anxiety and depression (Kubzansky, Gilthorpe, \& Goodman, 2013), whereas sedentary behavior had a negative association with mental well-being (Hamer, Stamatakis \& Mishra, 2010).

\subsubsection{Body Image}

Research indicates that higher BMI is a risk factor for body image dissatisfaction (van den Berg et al., 2007). Several publications showed that individuals with eating disorders also report higher levels of body dissatisfaction (Pickett et al., 2012). The same applies to those who have higher BMI (Mirza, Dawnavan, \& Yanovski, 2005). The research by Watkins, Christie \& Chally (2008) conducted on college-aged men showed that overweight individuals reported significantly higher body image dissatisfaction than underweight and normal weight individuals. The perception of overweight individuals is that they are lazy, sad, unattractive, and unintelligent (Duncan \& Klos, 2014). Severe obesity due to poor body image can cause or exaggerate depression (Dixon, Dixon, \& O'Brien, 2003). Hausenblas and Fallon (2006) meta-analyzed 121 studies and concluded that people who exercised had a more positive body image, as physical activity helped to improve body image in intervention programs. In addition, Hausenblas and Downs (2001) indicated that athletes in comparison to nonathletes have a more positive body image.

\subsubsection{Self-Control}

Self-control is positively associated with health behaviors, including healthy eating and physical activity (Hankonen, Kinnunen, Absetz, \& Jallinoja, 2014; Konttinen, Haukkala, Sarlio-Lahteenkorva, Silventoinen, \& Jousilahti, 2009). For an individual who wants to maintain his weight, needs to regulate dietary and exercise habits. Keller and Siegrist (2014) argued that there is a negative association between high BMI and dispositional self-control, and they suggested that self-control facilitates the successful dietary habits. Cotter and Lachman (2010) argued that sense of control is associated with lower health-related behaviors and lower levels of physical activity.

\subsection{Final Rationale}

Unlike variable-focused statistical methods, cluster analysis is a person-focused method that identifies homogeneous subgroups with similar characteristics (Agresti, 2007). Cluster analysis offers advantages over the alternative quantitative approaches as it aims to identify distinct, relatively homogeneous groups based on selected attributes (e.g., BMI). The use of cluster analysis can aid in the development of tailored interventions focused on modifiable health-related behaviors such as exercise and eating habits by identifying normal and overweight patterns of characteristics that are associated with specific psychological indicators. A previous study on Greek population (Georgiadis, Biddle, \& Stavrou, 2006) provided cluster profiles to identify dietary through motivation perspective. The results showed three groups of dieters based on psychological theories of self-determination and self-esteem. The first group included individuals with higher BMI and lower self-esteem, named "media victims". The second group had older individuals with high self-esteem, named "try to feel beautiful"; and the third group had older individuals with a lower BMI and the most positive psychological profile, named "older and experienced". The study of (Greene et al., 2011) used cluster analysis separately by sex, for eating and exercise related behaviors and psychosocial variables. Results showed three segments for each sex. Wirfalt and Jeffery (1998) explored the food choice patterns by cluster analysis and identified six patterns depending on 
the type of food. BMI and gender were significant differences across clusters.

Thus, this study examined and described the differences in adult individuals with different BMI concerning sociodemographic and psychological variables. We examined many variables to target in a spherical result. A fundamental principle is that understanding of all levels of individuals with high BMI and compares with individuals with normal BMI could be crucial for the development of multilevel interventions. In addition, this study used a cluster approach that identifies and describes behavioral and psychological patterns in adult population and examines the associations between behaviors, demographic and psychosocial variables. An initial effort is to classify the amount of existing information to make it manageable and meaningful. This classification of information will help practitioners to apply for effective interventions to change behavior.

\subsection{Purpose}

Therefore, the aim of the present study was to identify and characterize normal weight and overweight/obese patterns in adult Greek participants. In addition, to examine the associations between these patterns and demographic characteristics, behaviors, and psychosocial variables.

\section{Methods}

\subsection{Procedure}

Participants were living in Greece and were selected randomly by electronic invitations via email. The questionnaires were self-referenced and completed online. The completion of the survey required $30 \mathrm{~min}$ on average. Participants informed that the test was anonymous and that they were free to withdraw if they wanted.

\subsection{Participants}

Participants were 361adults with a mean age of 36.3 years who completed the online questionnaire. The majority of participants were women (67.3\%), single (68.6\%), and with mean years of exercise participation as 7.3. The weight status of the individuals was classified on the basis of BMI (weight/height ${ }^{2}$ ) as follows: a) normal weight $<24.9 \mathrm{~kg} / \mathrm{m}^{2}$ and b) overweight $/$ obese $>25 \mathrm{~kg} / \mathrm{m}^{2}$. Of 361 respondents, $52 \%$ were classified as normal weight and $48 \%$ as overweight/obese. Demographic characteristics are presented in Table 2.

\subsection{Measures}

Exercise: The Godin-Shephard Leisure-Time Exercise Questionnaire (Godin \& Shephard, 1985) was used to assess the self-reported exercise behavior. Participants reported their exercise habits during a typical week regarding frequency, duration, and intensity. Participants indicated how many times in a week they exercised vigorous, moderate, and light. Then, participants' answers for vigorous, moderate, and light exercise were multiplied by 9, 5, and 3 METs (metabolic equivalents), respectively, to obtain the exercise index. Then, they were classified into three groups according to their exercise index value: a) the active group (3: more than 24 units); b) the moderately active group (2: 14 - 23 units); and c) the insufficiently active group (1: less than 14 units). An additional question to record the type of sport: team 1) or individual 2) and the total years of participation in this sport was also included.

Dietary habits: These were assessed using the Eating Behavior Questionnaire (Bebetsos, Theodorakis, Laparidis, \& Chroni, 2000; Bebetsos, Chroni, \& Theodorakis, 2002), which records how often individuals consume healthy and unhealthy food during the previous month. The questionnaire was developed in such a way that it reflects Greek healthy and unhealthy dietary habits. The questionnaire consists a total of 33 questions, 22 of them reflecting the healthy eating behavior (e.g., "How many times last month did you eat fresh vegetables?") and 11 questions expressing the unhealthy eating behavior (e.g., "How many times last month did you drink soft drinks?"). Responses represented the frequency of consumption during the last month with five options: 1 (for 1 - 6 times per month), 2 (for 7 - 12 times per month), 3 (for 13 - 18 times per month), 4 (for 19 - 24 times per month), and 5 (for 25 - 30 times per month). The Cronbach's alpha for the scale was found to be 0.83 .

TPB measures of physical activity and healthy eating: Participants completed a questionnaire assessing attitude, intention, perceived behavioral control, attitude strength, and perceived knowledge of exercise and healthy eating habits according to the constructs of the TPB (Ajzen, 2002) as have been previously adapted to The Greek language by Theodorakis (1999). 
Attitude: It was assessed using the stem "To follow an exercise/healthy diet program during next month is for me...”. Answers were given in six bipolar opposite paired adjectives with a response scale ranging from 1 to 7 ("good - bad”, “unpleasant - pleasant”, “useful - useless”, “unattractive - attractive”, "boring - interesting”, "healthy - unhealthy”). Higher scores indicated more positive attitudes. The Cronbach’s alpha was found to be 0.78 for the exercise questions and 0.56 for the healthy eating questions. The low value of Cronbach's alpha for healthy dietary habits questionnaire was due to the sixth question that refers that healthy dietary habits will be pleasant or unpleasant. Many individuals, who have positive attitudes to other issues, consider that is unpleasant for them to follow healthy dietary habits.

Intention: It was assessed using three items with all responses ranging from 1 to 7 (e.g., "I intend to exercise/eat healthily”: very likely - very unlikely). Higher scores indicated higher intention. The Cronbach’s alpha was found to be 0.88 for exercise questions and 0.91 for healthy eating questions.

Perceived behavioral control: It was assessed using three items, with responses ranging from 1 to 7 (e.g., "It is totally up to me whether I will exercise/eat healthily or not": strongly disagree - strongly agree; "For me exercise/eat healthy is...”: very difficult - very easy). Higher scores indicated higher perceived behavioral control. The Cronbach's alpha was found to be 0.91 for exercise questions and 0.87 for healthy eating questions.

Attitude strength: It was assessed as an additional construct to the TPB model (Theodorakis, 1994). It was measured using four items (e.g., "I consider myself able to exercise/eat healthy”) with responses ranging from 1 to 7. Higher scores indicated stronger attitude strength. The Cronbach's alpha was found to be 0.83 for exercise questions and 0.72 for healthy eating questions.

Perceived knowledge: It was also assessed as an additional construct to the TPB model (Theodorakis, 1994). It was measured using four items (e.g., "Some people are very aware of the issue of exercise/healthy dietary habits, how informed do you think that you are on this topic") with responses ranging from 1 to 7 . Higher scores indicated higher perceived knowledge. The Cronbach's alpha was found to be 0.61 for exercise questions and 0.87 healthy eating questions.

Multidimensional health locus of control questionnaire: It comprised (Wallston, Wallston, \& De Vellis, 1978), 18 questions about health. Answers were classified into four factors: a) internality, which measures the extent to which a person feels that has the control of health; b) medical personnel powerful others, which measures the extent to which the person feels that medical professionals monitor his or her health; c) check of health, which measures the extent to which person checks his or her health; and d) health significance, which measures the extent that health improvement is a matter of luck. Responses were rated on a six-point scale from 1 (totally disagree) to 6 (totally agree). Higher scores indicated a higher positive preference for each subscale measure. The Cronbach's alpha for this scale was found to be 0.76 .

Psychological well-being: It was assessed using the 12-Item General Health Questionnaire (Goldberg \& Williams, 1988). It comprised 12 self-reported questions and responses were given on a four-point scale from 1 (very often) to 4 (very seldom). Answers were classified into a three-factor structure: a) psychological distress, which represents the psychological problems; b) social and emotional dysfunction, which combines the inability to social functions; and c) cognitive disorder, which represents the inability of cognitive judgment. Higher scores on each factor indicated susceptibility for a mental health disorder. The Cronbach's alpha was found to be 0.85 .

Body image: It was assessed using Body Dissatisfaction Questionnaire (Rand \& Wright, 2000). Individuals were asked to complete the questionnaire on a scale of nine items: a) the self-perception of their body image; b) the ideal body image; and c) the desired body for their body image. The difference between self-perception, body image and the ideal body image gives the measure of "body dissatisfaction," which takes the values of 1 (satisfied), 2 (low satisfied), 3 (not satisfied), respectively, if there are 0,1 , or $>1$ units of difference. The difference between self-perception of body image and desired body image gives the variable of "body desire", which shows the size of the desired change in body image. The values of this variable are 1 (if individual wants to raise weight), 2 (if a person wants a stable weight), and 3 (if individual wants to lose weight), respectively, if the difference is $<-1$ (negative number), 0 , or $>1$ (positive number). High scores in both body dissatisfaction and body desire variables indicated that individual is not satisfied with his or her body and wants to lose weight.

Self-Control: It was assessed using Self-Control Questionnaire. It consisted (Tangney, Baumeister, \& Boone, 2004) of 36 self-reported questions (e.g., “I am good at resisting temptations”). Responses were rated on a five-point scale from 1 (not at all) to 5 (very much). Higher scores indicated better self-control. The Cronbach’s alpha for this scale was found to be 0.88 . 


\subsection{Statistical Analysis}

Statistical analysis was performed using SPSS software, version 20. A cluster analysis was performed to identify homogeneous groups based on similar characteristics. The K-means cluster, a nonhierarchical clustering method used with squared Euclidean distance as the similarity measure. All variables were converted to $z$-scores. The values in the range of \pm 0.5 showed relatively higher, or lower scores and values higher/lower of \pm 1.0 were considered very high for the respective behaviors. The 2 cluster solution was selected after tested the cases of clustering stability, which applied for testing of 2, 3, 4 and 5 cluster cases.

\section{Results}

\subsection{Results in Cluster Analysis}

The analysis showed two clusters; various cluster procedures were tested before to show which was the most meaningful. The means of each cluster reported in $z$-scores, nonstandardized means, and standard deviations presented in Table 2. Cluster 1 comprised 231 individuals with a mean BMI of 24.61 and cluster 2 comprised 130 individuals with a mean BMI of 28.18. The comparison of clusters showed that cluster 1 showed significantly higher scores on the values of TPB, leisure time activity, healthy eating behavior, and the variables of health locus of control. In addition, cluster 1 showed significantly lower scores on the variables of psychological distress and ideal body (values are displayed in Table 1).

Table 1. Mean scores, standard deviations, z-scores for the clusters and t-test results.

\begin{tabular}{|c|c|c|c|c|c|c|c|c|}
\hline & \multicolumn{3}{|c|}{ Cluster 1} & \multicolumn{3}{|c|}{ Cluster 2} & \multicolumn{2}{|c|}{ t-test } \\
\hline & $\mathbf{M}$ & SD & Mean z & $\mathbf{M}$ & SD & Mean z & $\mathbf{t}$ & $p$ \\
\hline BMI & 24.61 & 4.56 & -0.24 & 28.18 & 5.80 & 0.41 & -6.20 & 0.00 \\
\hline Leisure time activity & 44.67 & 25.49 & 0.28 & 24.90 & 18.01 & -0.50 & 8.53 & 0.00 \\
\hline Healthy eating behavior & 2.09 & 0.55 & 0.24 & 1.72 & 0.45 & -0.44 & 6.75 & 0.02 \\
\hline $\begin{array}{l}\text { Exercise } \\
\text { Attitudes }\end{array}$ & 40.42 & 3.03 & 0.30 & 36.80 & 5.27 & -0.51 & 7.89 & 0.00 \\
\hline Intention & 19.00 & 3.09 & 0.35 & 14.66 & 5.14 & -0.61 & 8.76 & 0.00 \\
\hline Perceived behavioral control & 18.09 & 3.63 & 0.40 & 12.53 & 5.18 & -0.70 & 10.80 & 0.00 \\
\hline Attitude strength & 24.33 & 3.84 & 0.44 & 17.61 & 5.22 & -0.77 & 12.80 & 0.01 \\
\hline Knowledge & 22.36 & 4.82 & 0.07 & 17.09 & 5.56 & -0.12 & 9.40 & 0.39 \\
\hline $\begin{array}{l}\text { Healthy eating } \\
\text { Attitudes }\end{array}$ & 40.14 & 2.52 & 0.77 & 36.56 & 5.18 & -0.57 & 7.38 & 0.00 \\
\hline Intentions & 18.83 & 3.19 & 0.36 & 14.65 & 4.68 & -0.64 & 9.03 & 0.00 \\
\hline Perceived behavioral control & 18.12 & 2.64 & 0.47 & 12.80 & 4.26 & -0.83 & 12.87 & 0.00 \\
\hline Attitude strength & 22.73 & 3.96 & 0.42 & 16.72 & 5.05 & -0.74 & 11.68 & 0.03 \\
\hline Knowledge & 21.65 & 4.98 & 0.25 & 19.19 & 5.23 & -0.44 & 7.14 & 0.02 \\
\hline $\begin{array}{c}\text { Health locus of control } \\
\text { Internal }\end{array}$ & 20.74 & 2.41 & 0.33 & 18.06 & 2.97 & -0.58 & 8.93 & 0.00 \\
\hline Health professionals & 16.91 & 2.64 & 0.10 & 15.69 & 4.49 & -0.16 & 2.71 & 0.00 \\
\hline Check health & 15.83 & 2.44 & 0.25 & 13.90 & 2.39 & -0.45 & 7.38 & 0.00 \\
\hline Health significance & 21.41 & 2.74 & 0.24 & 19.39 & 3.12 & -0.41 & 5.86 & 0.02 \\
\hline $\begin{array}{l}\text { General Health: } \\
\text { Psychological distress }\end{array}$ & 10.63 & 2.71 & -0.22 & 12.56 & 3.43 & 0.39 & -5.52 & 0.00 \\
\hline $\begin{array}{c}\text { Social and emotional } \\
\text { dysfunction }\end{array}$ & 7.34 & 2.64 & -0.16 & 8.63 & 2.75 & 0.30 & -4.39 & 0.43 \\
\hline Cognitive disorder & 5.38 & 1.80 & -0.16 & 6.26 & 1.92 & 0.30 & -4.37 & 0.56 \\
\hline Body image dissatisfaction & 2.08 & 0.69 & -0.23 & 2.53 & 0.63 & 0.40 & -6.07 & 0.24 \\
\hline Ideal body & 2.53 & 0.63 & -0.14 & 2.84 & 0.45 & 0.24 & -3.90 & 0.00 \\
\hline Self-control & 132.70 & 16.52 & 0.35 & 114.89 & 15.83 & -0.62 & 10.09 & 0.64 \\
\hline
\end{tabular}




\subsection{Cluster Analysis of Independent Variables}

Percentages of cluster representation are presented in Table 2. One-way analysis of variance showed statistically significant differences within the characteristics of BMI, $F_{(1,359)}=43.61, p<0.00$; years of exercise participation, $F_{(1,359)}=7.81, p<0.00$; and sport type, $F_{(1,359)}=28.62, p<0.00$. The gender, age, marital status, education, and region of residence of the groups showed no significant differences.

Table 2. Demographic characteristics and percentages of cluster representations.

\begin{tabular}{|c|c|c|c|c|c|c|c|c|}
\hline & \multicolumn{2}{|c|}{ Demographic characteristics } & \multicolumn{2}{|c|}{ Cluster $1 \mathrm{~N}=231$} & \multicolumn{2}{|c|}{ Cluster $2 \mathrm{~N}=130$} & \multirow[b]{2}{*}{$\mathbf{F}$} & \multirow[b]{2}{*}{$p$} \\
\hline & $\mathbf{N}$ & $\%$ & $\mathbf{N}$ & $\%$ & $\mathbf{N}$ & $\%$ & & \\
\hline Gender & & & & & & & 0.37 & 0.54 \\
\hline Males & 119 & 32.9 & 79 & 66.3 & 40 & 33.6 & & \\
\hline Females & 242 & 67.1 & 152 & 62.8 & 90 & 37.2 & & \\
\hline BMI & & & & & & & 43.61 & 0.00 \\
\hline Underweight & 8 & 2.2 & 7 & 87.5 & 1 & 12.5 & & \\
\hline Normal & 178 & 49.3 & 143 & 80.3 & 35 & 19.7 & & \\
\hline Overweight & 103 & 28.5 & 49 & 52.4 & 54 & 52.4 & & \\
\hline Obese & 72 & 19.9 & 32 & 44.4 & 40 & 55.6 & & \\
\hline Age & & & & & & & 4.26 & 0.04 \\
\hline$<20$ & 18 & 4.9 & 13 & 72.2 & 5 & 27.7 & & \\
\hline $21-35$ & 199 & 55.1 & 134 & 67.5 & 65 & 32.7 & & \\
\hline $36-50$ & 91 & 25.2 & 56 & 61.5 & 35 & 38.5 & & \\
\hline$>50$ & 53 & 14.6 & 28 & 52.8 & 25 & 47.2 & & \\
\hline Marital status & & & & & & & 2.48 & 0.11 \\
\hline Married & 151 & 41.8 & 90 & 59.6 & 61 & 40.4 & & \\
\hline In relationship & 13 & 3.6 & 8 & 61.5 & 5 & 38.5 & & \\
\hline Single & 197 & 54.5 & 133 & 52.8 & 64 & 32.8 & & \\
\hline Education & & & & & & & 4.91 & 0.02 \\
\hline MSc-PhD & 10 & 2.7 & 9 & 90.0 & 1 & 10.0 & & \\
\hline Bachelor & 106 & 29.3 & 70 & 65.1 & 36 & 34.9 & & \\
\hline High school & 156 & 43.2 & 106 & 67.5 & 50 & 32.5 & & \\
\hline Elementary & 74 & 20.4 & 37 & 75 & 37 & 25 & & \\
\hline Other & 15 & 4.1 & 9 & 71.4 & 6 & 28.6 & & \\
\hline Type of sport & & & & & & & 28.62 & 0.00 \\
\hline No participation & 123 & 34.0 & 59 & 47.9 & 64 & 52.1 & & \\
\hline Individual sport & 73 & 20.2 & 45 & 61.6 & 28 & 38.4 & & \\
\hline Team sport & 162 & 44.8 & 125 & 77.2 & 37 & 22.8 & & \\
\hline $\begin{array}{l}\text { Years of exercise } \\
\text { participation }\end{array}$ & & & & & & & 7.81 & 0.00 \\
\hline$<5$ & 74 & 20.4 & 46 & 62.1 & 28 & 37.9 & & \\
\hline $6-10$ & 68 & 18.8 & 49 & 80.6 & 19 & 27.9 & & \\
\hline $11-20$ & 62 & 17.1 & 50 & 81.3 & 12 & 19.4 & & \\
\hline$>20$ & 33 & 9.1 & 26 & 72.3 & 7 & 18.8 & & \\
\hline Region & & & & & & & 0.19 & 0.66 \\
\hline Urban & 78 & 21.6 & 42 & 53.8 & 36 & 46.2 & & \\
\hline Suburban & 27 & 7.4 & 16 & 59.3 & 11 & 40.7 & & \\
\hline Rural & 4 & 1.1 & 3 & 66.7 & 1 & 33.3 & & \\
\hline
\end{tabular}




\section{Discussion}

\subsection{Cluster Profiles Classifications}

In our paper identified two distinct clusters one for healthy and the second for the unhealthy segment. Enough researchers using cluster analysis to associate different variables that are related to BMI. Green et al. (2015) examined individuals with a BMI of more than $30 \mathrm{~kg} / \mathrm{m}^{2}$, using cluster analysis concerning factors such as health, demographics, and behavioral characteristics. The results showed six subgroups that shared common features. Another research of cluster analysis in college students showed group differences in BMI. The high-risk group had highest emotional eating, emotional distress, lowest intake of fruits and vegetables, and lowest exercise level (Greene et al., 2011). Ogden et al. (2012) used cluster analysis to identify subgroups at weight loss maintenance. Their results showed four different segments. The first segment comprised healthy individuals who were exercising more and had a normal BMI. The second segment comprised individuals who wanted to lose weight with high levels of stress and depression and had a BMI of $28.6 \mathrm{~kg} / \mathrm{m}^{2}$. The third segment comprised individuals who successfully reduced and maintained their weight with a BMI of $23.3 \mathrm{~kg} / \mathrm{m}^{2}$; and the fourth group was the unhealthy one, with fewer exercise and more health problems and with a BMI of 26.1 $\mathrm{kg} / \mathrm{m}^{2}$. Our results are clearer and easy to explain because of 2 segments. A further analysis will give more accurate representations.

The healthy segment is based on healthier behaviors and concerns normal weight individuals. The opposite occurs in the unhealthy segment, which involves overweight individuals. Approximately two-third of the participants were categorized in the healthy segment $(66.1 \%)$ and one-third in the unhealthy segment $(33.9 \%)$. The healthy segment had a BMI mean score of 24.61, which is classified in the normal weight category. The unhealthy segment appeared a BMI mean score of 28.18, which is categorized in the overweight category. Regarding the sociodemographic characteristics, the segments had significant differences in BMI, age, education, type of sport and the total years of exercise participation.

\subsection{Cluster Profiles in Relation to Physical Activity and Eating Behavior}

Concerning physical activity, the identified patterns were the expected direction. Individuals in the healhty segment had higher levels of leisure time activity and more years of exercise participation. Similarly, the values in healthy eating behaviors were higher. In addition, they tend to have more positive attitudes and intentions for healthy eating and physical activity. An important conclusion is that they appeared higher scores in knowledge for physical activity and healthy eating. In accordance, the cluster analysis of Monda and Popkin (2005) showed that youth who were active had significantly decreased odds of having an abnormal weight.

\subsection{Cluster Profiles in Relation to Health Perceptions}

The cluster classification with health perceptions showed that healthy segment individuals evaluated more active the significance of health. They are checking more their health, and they value more the advises that receive from doctors and health professionals. We conclude that a positive health perception is probably related to a normal BMI because of a positive attitude to life. In the research of Ford, Moriarty, Zack, Mokdad, and Chapman (2001), the quality of life was better for normal BMI individuals than underweight or overweight individuals. Similarly, the findings of Helmer, Krämer, and Mikolajczyk (2012), detected associations between the behaviors of physical activity and healthy eating with health locus of control variables. An important conclusion is this relation of health perceptions and health management. Further investigation is proposed; that could be based on the relationship between health knowledge and attitude for healthy behaviors such as physical activity and healthy eating. Childs and adolescents could more quickly develop positive health behaviors, and emphasis should be placed on educational programs. Melnyk and colleagues (2006) suggested that adolescents who are engaged in healthy lifestyles were related to healthier behaviors and choices. In a most recent intervention of Melnyk et al. (2009), adolescents increased healthy lifestyle choices when they increased strong beliefs and knowledge.

\subsection{Cluster Profiles in Relation to Psychological Variables}

In our research, the segments produced significant differences between the values that are related to psychological distress. A closer look showed that all the values were higher in the unhealthy segment. Those results were 
similar to the research of Marchand, Beauregard and Blanc (2015), which supports that psychological distress is a risk for obesity. Brandheim, Rantakeisu, and Starrin (2013) studied the association between psychological distress and BMI in a sample of 68,000 Swedish adults. The results showed a decrease in psychological distress with increasing age regardless BMI. Besides, higher psychological distress appeared to obese II (BMI > 35 $\mathrm{kg} / \mathrm{m}^{2}$ ) in comparison with the other BMI categories (obese, overweight, and normal weight).

The results showed that unhealthy segment appeared higher social and emotional dysfunction. That are in agreement with the study by Desai, Manley, MPhil, Desai and Potenza (2009). They showed that obese individuals may have restrictions in social functioning, lower social activity and may are diagnosed with depression and anxiety. Strongest associations appeared in women. In our findings, there was not a difference between men and women. An important implication of these findings is the stigmatization of overweight and obese individuals for emotional dysfunction (Major, Eliezer, \& Rieck, 2012). In addition, the meta-analysis by Luppino et al. (2010) supported that obesity is associated with increased risk of depression. Obese individuals appeared a 55\% increased risk of developing depression.

Cognitive disorder variables showed significant differences between healthy and unhealthy segments. The study by Cronk, Johnson and Burns (2010), referred that higher BMI is associated with brain changes, a decline in mild cognitive impairment and risk of Alzheimer disease. Furthermore, Whitmer, Gunderson, Barrett-Connor, Quesenberry, and Yaffe (2005) suggested that high BMI in middle age increases the risk of future dementia. However, according to Atti and colleagues (2007), high BMI in older adults is associated with the protection of development of dementia and low BMI is associated with an increased risk.

Healthy and unhealthy segments are associated with body image dissatisfaction and high scores of BMI. Body image dissatisfaction is related to obesity (Sarwer, Wadden, \& Foster, 1998) and more women than men with an abnormal BMI showed higher body image perception (Santos, Nahas, De Sousa, Del Duca, \& Peres, 2011 ). Mills, Jadd, and Key (2012) examined ideal body perception and found that women wanted a thinner body size and men a more muscular one. Furthermore, the body image perception was influenced by body norms. In our results, cluster analysis did not show significant differences between the two segments in the variable of an ideal body. Moreover, individuals in healthy segment showed higher self-control than those in the unhealthy segment, even though the results were not statistically significant as was expected. Fan and Jin (2013) measured selfcontrol and found that obese individuals had lower self-control than normal weight.

\subsection{Limitations and Future Research}

The findings of the study should be considered within the context of its limitations. First, the use of BMI classification is not a reliable indicator because is not based on body composition and is not derived from objectively measured weight and height. Self-reported measures may have affect classification of BMI. Furthermore, the sample size is not providing sufficient statistical results and in BMI underweight group the sample is very small $(\mathrm{N}=7)$. Cluster analysis is used to discover structures in data without providing an interpretation. Nevertheless, although all of the variables have been explored in previous literature separately, no previous study used a cluster analysis to verify the segmentation of these variables to a healthy and unhealthy profile as this study did. These limitations are necessary for the development of effective interventions as like for future research.

For future studies, we suggest a further examination of the patterns of behaviors using the variables of cluster analysis to show the extent of the influence of each variable. We support that this procedure will be useful for weight loss treatments and the development of public health interventions. The findings of our study show the implications for the prevention of obesity and co-existing problems, disordered body image, malnutrition, fewer years of exercise participation, and high psychological distress. Accordingly, we suggest the need for research to provide messages about healthy eating, physical activity, general health, and especially, targeting the positive attitudes and intentions to healthy eating and physical activity in combination with healthy eating behaviors. In addition, future studies could investigate the role of different segments of the diverse population to different countries. Also, we should consider that a woman had the opposite ideal body image than a man (thin or muscular respectively), and it should be examined separately.

\section{Conclusion}

This paper addresses a topic with public health relevance using many factors. The present novelty comprises of the fact that a combination of several health-related psychological variables are used in studying overweight and 
obesity in addition to the used demographic characteristics and the level of exercise and eating habits. The results imply that unhealthy segment shows a high association between increased BMI, low physical activity, low healthy eating, high psychological distress, low self-control, low body image, negative attitudes, and intentions toward healthy eating and physical activity. This research builds on existing knowledge by giving a better understanding of physical activity and healthy eating behaviors in different BMI groups concerning the above variables.

\section{References}

Agresti, A. (2007). An Introduction to Categorical Data Analysis (2nd ed.). New Jersey: Hoboken. http://dx.doi.org/10.1002/0470114754

Ajzen, I. (1991). The Theory of Planned Behavior. Organizational Behavior and Human Decision Processes, 50, $179-211$. http://dx.doi.org/10.1016/0749-5978(91)90020-T

Ajzen, I. (2002). Constructing a Theory of Planned Behavior Questionnaire. http://www-unix.oit.umass.edu/ aizen/pdf/tpb.measurement.pdf

Al-Nakeeb, Y., Dodd, L., Lyons, M., Collins, P., \& Al-Nuaim, A. (2014). A Cluster Analysis of Lifestyle and Health Habits of Youth from Two Geographically and Culturally Diverse Countries. Open Journal of Preventive Medicine, 4, 193-203. http://dx.doi.org/10.4236/ojpm.2014.44025

Atti, R., Palmer, K., Volpato, S., Winblad, B., De Ronchi, D., \& Fratiglioni, L. (2007). Late-Life Body Mass Index and Dementia Incidence: Nine-Year Follow-Up Data from the Kungsholmen Project. Journal of the American Geriatrics Society, 111, 111-116.

Bauman, A., Allman-Farinelli, M., Huxley, R., \& James, W. (2008). Leisure-Time Physical Activity alone May Not Be a Sufficient Public Health Approach to Prevent Obesity_A Focus on China. Obesity Reviews, 9, 119-126. http://dx.doi.org/10.1111/j.1467-789X.2007.00452.x

Bauman, A., Reis, R. S., Sallis, J. F., Wells, J. C., Loos, R. J., \& Martin, B. W. (2012). Correlates of Physical Activity: Why Are Some People Physically Active and Others Not? The Lancet, 380, 258-271. http://dx.doi.org/10.1016/S0140-6736(12)60735-1

Bebetsos, E., Chroni, S., \& Theodorakis, Y. (2002). Physical Active Students’ Intentions and Self-Efficacy towards Healthy Eating. Psychological Reports, 91, 485-495. http://dx.doi.org/10.2466/pr0.2002.91.2.485

Bebetsos, E., Theodorakis, I., Laparidis, K., \& Chroni, S. (2000). Reliability and Validity of a Self-Confidence Scale for a Healthy Eating Questionnaire. Health and Sport Performance (in Greek), 3, 191-203.

Bennett, P., Moore, L., Smith, A., Murphy, S., \& Smith, C. (1994). Health Locus of Control and Value for Health as Predictors of Dietary Behaviour. Psychology \& Health, 41-54. http://dx.doi.org/10.1080/08870449408401935

Brandheim, S., Rantakeisu, U., \& Starrin, B. (2013). BMI and Psychological Distress in 68,000 Swedish Adults: A Weak Association When Controlling for an Age-Gender Combination. BMC Public Health, 13, 68. http://dx.doi.org/10.1186/1471-2458-13-68

Buchan, D., Ollis, S., Thomas, N., \& Baker, J. (2012). Physical Activity Behaviour: An Overview of Current and Emergent Theoretical Practices. Journal of Obesity, 2012, Article ID: 546459. http://dx.doi.org/10.1155/2012/546459

Catenacci, V., Ogden, L., Stuht, J., Phelan, S., Wing, R., Hill, J. et al. (2012). Physical Activity Patterns in the National Weight Control Registry. Obesity, 16, 153-161. http://dx.doi.org/10.1038/oby.2007.6

Chan, R., \& Woo, J. (2010). Prevention of Overweight and Obesity: How Effective Is the Current Public Health Approach. International Journal of Environmental Research and Public Health, 7, 765-783. http://dx.doi.org/10.3390/ijerph7030765

Chatzisarantis, N., Hagger, M., Biddle, S., \& Smith, B. (2005). The Stability of the Attitude-Intention Relationship in the Context of Physical Activity. Journal of Sports Sciences, 23, 49-61. http://dx.doi.org/10.1080/02640410410001730070

Chrysochou, P., Askegaard, S., Grunert, K. G., \& Kristensen, D. (2010). Social Discourses of Healthy Eating. A Market Segmentation Approach. Appetite, 55, 288-297. http://dx.doi.org/10.1016/j.appet.2010.06.015

Cotter, K., \& Lachman, M. (2010). No Strain, No Gain: Psychosocial Predictors of Physical Activity across the Adult Lifespan. Journal of Physical Activity \& Health, 7, 584-594.

Cronk, B., Johnson, K., \& Burns, J. (2010). Body Mass Index and Cognitive Decline in Mild Cognitive Impairment. Alzheimer Disease and Associated Disorders, 24, 126-130. http://dx.doi.org/10.1097/WAD.0b013e3181a6bf3f

De Wit, L., Luppino, F., van Straten, A., Penninx, B., Zitman, F., \& Cuijpers, P. (2010). Depression and Obesity: A Meta-Analysis of Community-Based Studies. Psychiatry Research, 178, 230-235. http://dx.doi.org/10.1016/j.psychres.2009.04.015

Desai, R., Manley, M., MPhil, M., Desai, M., \& Potenza, M. (2009). Gender Differences in the Association between Body 
Mass Index and Psychopathology. CNS Spectrums, 14, 372-383.

Dixon, J. B., Dixon, M. E., \& O’Brien, P. E. (2003). Depression in Association with Severe Obesity Changes with Weight Loss. Archives of Internal Medicine, 163, 2058-2065. http://dx.doi.org/10.1001/archinte.163.17.2058

Doganis, G., Theodorakis, I., \& Bagiatis, K. (1991). Self-Esteem and Locus of Control in Adult Female Fitness Program Participants. International Journal of Sport Psychology, 22, 154-164.

Duncan, M., \& Klos, M. (2014). Paradoxes of the Flesh Emotion and Contradiction in Fitness/Beauty Magazine Discourse. Journal of Sport \& Social Issues, 38, 245-262. http://dx.doi.org/10.1177/0193723512467190

Fan, M., \& Jin, Y. (2013). Obesity and Self-Control: Food Consumption, Physical Activity, and Weight-Loss Intention. Applied Economic Perspectives and Policy, 36, 125-145. http://dx.doi.org/10.1093/aepp/ppt034

Fila, S., \& Smith, C. (2006). Applying the Theory of Planned Behavior to Healthy Eating Behaviors in Urban Native American Youth. International Journal of Behavioral Nutrition and Physical Activity, 3, 11. http://dx.doi.org/10.1186/1479-5868-3-11

Ford, E., Moriarty, D., Zack, M., Mokdad, A., \& Chapman, D. (2001). Self-Reported Body Mass Index and Health-Related Quality of Life: Findings from the Behavioral Risk Factor Surveillance System. Obesity, 9, 21-31. http://dx.doi.org/10.1038/oby.2001.4

Georgiadis, M., Biddle, S., \& Stavrou, N. (2006). Motivation for Weight-Loss Diets: A Clustering, Longitudinal Field Study Using Self-Esteem and Self-Determination Theory Perspectives. Health Education Journal, 65, 53-72.

http://dx.doi.org/10.1177/0017896906066067

Glanz, K., Basil, M., Maibach, E., Goldeberg, J., \& Snyder, D. (1998). Why Americans Eat What They Do: Taste, Nutrition, Cost, Convenience, and Weight Control Concerns as Influences on Food Consumption. Journal of the American Dietetic Association, 98, 1118-1126. http://dx.doi.org/10.1016/S0002-8223(98)00260-0

Godin, G., \& Shephard, R. (1985). A Simple Method to Assess Exercise Behavior in the Community. Canadian Journal of Applied Sport Sciences, 10, 141-146.

Goldberg, D., \& Williams, P. (1988). A User's Guide to the General Health Questionnaire. Windsor: NFER-Nelson.

Green, A., Strong, M., Razak, F., Subramanian, V., Relton, C., \& Bissell, P. (2015). Who Are the Obese? A Cluster Analysis Exploring Subgroups of the Obese. Journal of Public Health: Oxford Journals, Epub ahead of print.

Greene, G., Schembre, S., White, A., Hoerr, S., Lohse, B., Shoff, S. et al. (2011). Identifying Clusters of College Students at Elevated Health Risk Based on Eating and Exercise Behaviors and Psychosocial Determinants of Body Weight. Journal of the American Dietetic Association, 111, 394-400. http://dx.doi.org/10.1016/j.jada.2010.11.011

Grønhøj, A., Bech-Larsen, T., Chan, K., \& Tsang, L. (2012). Using Theory of Planned Behavior to Predict Healthy Eating among Danish Adolescents. Health Education, 113, 4-17. http://dx.doi.org/10.1108/09654281311293600

Grotz, M., Hapke, U., Lampert, T., \& Baumeister, H. (2011). Health Locus of Control and Health Behaviour: Results from a Nationally Representative Survey. Psychology, Health \& Medicine, 16, 129-140. http://dx.doi.org/10.1080/13548506.2010.521570

Hallal, C., Reichert, F., Siqueira, V., Dumith, C., Bastos, P., da Silva, C. et al. (2008). Correlates of Leisure-Time Physical Activity Differ by Body-Mass-Index Status in Brazilian Adults. Journal of Physical Activity \& Health, 5, 571-578.

Hamer, M., Stamatakis, E., \& Mishra, G. D. (2010). Television- and Screen-Based Activity and Mental Well-Being in Adults. American Journal of Preventive Medicine, 38, 375-380. http://dx.doi.org/10.1016/j.amepre.2009.12.030

Hankonen, N., Kinnunen, M., Absetz, P., \& Jallinoja, P. (2014). Why Do People High in Self-Control Eat More Healthily? Social Cognitions as Mediators. Annals of Behavioral Medicine, 47, 242-248.

http://dx.doi.org/10.1007/s12160-013-9535-1

Hausenblas, A., \& Fallon, E. (2006). Exercise and Body Image: A Meta-Analysis. Psychology \& Health, 21, 33-47. http://dx.doi.org/10.1080/14768320500105270

Hausenblas, H., \& Downs, D. (2001). Comparison of Body Image between Athletes and Nonathletes: A Meta-Analytic Review. Journal of Applied Sport Psychology, 13, 323-339. http://dx.doi.org/10.1080/104132001753144437

Havitz, M., Kaczynski, A., \& Mannell, R. (2012). Exploring Relationships between Physical Activity, Leisure Involvement, Self-Efficacy, and Motivation via Participant Segmentation. Leisure Sciences, 35, 45-62. http://dx.doi.org/10.1080/01490400.2013.739890

Helmer, S., Krämer, A., \& Mikolajczyk, R. (2012). Health-Related Locus of Control and Health Behaviour among University Students in North Rhine Westphalia, Germany. BMC Research Notes, 5, 703.

http://dx.doi.org/10.1186/1756-0500-5-703

http://www.who.int/ (2015). Retrieved from World Health Organization.

http://www.who.int/mediacentre/factsheets/fs311/en/ 
Keller, C., \& Siegrist, M. (2014). Successful and Unsuccessful Restrained Eating. Does Dispositional Self-Control Matter? Appetite, 74, 101-106. http://dx.doi.org/10.1016/j.appet.2013.11.019

Konttinen, H., Haukkala, A., Sarlio-Lahteenkorva, S., Silventoinen, K., \& Jousilahti, P. (2009). Eating Styles, Self-Control and Obesity Indicators. The Moderating Role of Obesity Status and Dieting History on Restrained Eating. Appetite, 53, 131-134. http://dx.doi.org/10.1016/j.appet.2009.05.001

Kubzansky, L., Gilthorpe, M., \& Goodman, E. (2013). A Prospective Study of Psychological Distress and Weight Status in Adolescents/Young Adults. Annals of Behavioral Medicine, 43, 219-228. http://dx.doi.org/10.1007/s12160-011-9323-8

Liao, Y., Harada, K., Shibata, A., Ishii, K., Oka, K., Nakamura, Y. et al. (2012). Association of Self-Reported Physical Activity Patterns and Socio-Demographic Factors among Normal-Weight and Overweight Japanese Men. BMC Public Health, 12, 278. http://dx.doi.org/10.1186/1471-2458-12-278

Luppino, F., de Wit, L., Bouvy, P., Stijnen, T., Cuijpers, P., Penninx, B. et al. (2010). Overweight, Obesity, and Depression: A Systematic Review and Meta-Analysis of Longitudinal Studies. Archives of General Psychiatry, 67, 220-229. http://dx.doi.org/10.1001/archgenpsychiatry.2010.2

Major, B., Eliezer, D., \& Rieck, H. (2012). The Psychological Weight of Weight Stigma. Social Psychological and Personality Science, 3, 651-658. http://dx.doi.org/10.1177/1948550611434400

Marchand, A., Beauregard, N., \& Blanc, M. (2015). Work and Non-Work Stressors, Psychological Distress and Obesity: Evidence from a 14-Year Study on Canadian Workers. BMJ Open, 5, e006285. http://dx.doi.org/10.1136/bmjopen-2014-006285

Melnyk, M., Jacobson, D., Kelly, S., O’Haver, J., Small, L., \& Mays, Z. (2009). Improving the Mental Health, Healthy Lifestyle Choices, and Physical Health of Hispanic Adolescents: A Randomized Controlled Pilot Study. Journal of School Health, 79, 575-584. http://dx.doi.org/10.1111/j.1746-1561.2009.00451.x

Melnyk, M., Small, L., Morrison-Beedy, D., Strasser, A., Spath, L., Kreipe, R. et al. (2006). Mental Health Correlates of Healthy Lifestyle Attitudes, Beliefs, Choices, and Behaviors in Overweight Adolescents. Journal of Pediatric Health Care, 20, 401-406. http://dx.doi.org/10.1016/j.pedhc.2006.03.004

Mills, J., Jadd, R., \& Key, B. (2012). Wanting a Body That's Better than Average: The Effect of Manipulated Body Norms on Ideal Body Size Perception. Body Image, 9, 365-372. http://dx.doi.org/10.1016/j.bodyim.2012.03.004

Mirza, N., Dawnavan, D., \& Yanovski, J. (2005). Body Dissatisfaction, Self-Esteem, and Overweight among Inner-City Hispanic Children and Adolescents. Journal of Adolescent Health, 36, 267.e16-267.e20. http://dx.doi.org/10.1016/j.jadohealth.2004.02.033

Monda, K., \& Popkin, B. (2005). Cluster Analysis Methods Help to Clarify the Activity-BMI Relationship of Chinese Youth. Obesity Research, 13, 1042-1051. http://dx.doi.org/10.1038/oby.2005.122

Ogden, L., Stroebele, N., Wyatt, H., Catenacci, V., Peters, J., Stuht, J. et al. (2012). Cluster Analysis of the National Weight Control Registry to Identify Distinct Subgroups Maintaining Successful Weight Loss. Obesity, 20, 2039-2047. http://dx.doi.org/10.1038/oby.2012.79

Pickett, L., Ginsburg, H., Mendez, R., Lim, D., Blankenship, K., Foster, L. et al. (2012). Ajzen’s Theory of Planned Behavior as It Relates to Eating Disorders and Body Satisfaction. North American Journal of Psychology, 14, 339.

Poobalan, A., Aucott, L., Clarke, A., \& Smith, W. C. (2012). Physical Activity Attitudes, Intentions and Behaviour among 18-25 Year Olds: A Mixed Method Study. BMC Public Health, 12, 640. http://dx.doi.org/10.1186/1471-2458-12-640

Rand, C., \& Wright, B. (2000). Continuity and Change in the Evaluation of Ideal and Acceptable Body Sizes across a Wide Age Span. International Journal of Eating Disorders, 28, 90-100. http://dx.doi.org/10.1002/(SICI)1098-108X(200007)28:1<90::AID-EAT11>3.0.CO;2-P

Roefs, A., \& Jansen, A. (2010). Control Yourself or Just Eat What You Like? Weight Gain Over a Year Is Predicted by an Interactive Effect of Response Inhibition and Implicit Preference for Snack Foods. Health Psychology, 4, 389-393.

Santos, S., Nahas, M., De Sousa, D., Del Duca, G., \& Peres, K. (2011). Prevalence and Associated Factors with Body Image Dissatisfaction among Adults in Southern Brazil: A Population-Based Study. Body Image, 8, 427-431. http://dx.doi.org/10.1016/j.bodyim.2011.05.009

Sarwer, D., Wadden, T., \& Foster, G. (1998). Assessment of Body Image Dissatisfaction in Obese Women: Specificity, Severity, and Clinical Significance. Journal of Consulting and Clinical Psychology, 66, 651-654. http://dx.doi.org/10.1037/0022-006X.66.4.651

Scott, K., McGee, M., Wells, E., \& Oakley Browne, M. (2008). Obesity and Mental Disorders in the Adult General Population. Journal of Psychosomatic Research, 64, 97-105. http://dx.doi.org/10.1016/j.jpsychores.2007.09.006

Tangney, J., Baumeister, R., \& Boone, A. (2004). High Self-Control Predicts Good Adjustment, Less Pathology, Better Grades, and Interpersonal Success. Journal of Personality, 72, 271-324. http://dx.doi.org/10.1111/j.0022-3506.2004.00263.x 
Theodorakis, Y. (1994). Planned Behabior, Attitude Strength, Role Identity, and the Prediction of Exercise Behavior. Sport Psychologist, 8, 149-165.

Theodorakis, Y. (1999). Body Image, Body Cathexis and Mental Health. Athletic Performance and Health, 91-110.

Titchener, K., \& Wong, Q. (2015). A Weighty Issue: Explaining the Association between Body Mass Index and Appearance-Based Social Anxiety. Eating Behaviors, 16, 13-16. http://dx.doi.org/10.1016/j.eatbeh.2014.10.005

Van den Berg, P., Paxton, S., Keery, H., Wall, M., Guo, J., \& Neumark-Sztainer, D. (2007). Body Dissatisfaction and Body Comparison with Media Images in Males and Females. Body Image, 4, 257-268.

http://dx.doi.org/10.1016/j.bodyim.2007.04.003

Wagner, A., Simon, C., Ducimetière, P., Montaye, M., Bongard, V., Yarnell, J. et al. (2001). Leisure-Time Physical Activity and Regular Walking or Cycling to Work Are Associated with Adiposity and 5 y Weight Gain in Middle-Aged Men: The PRIME Study. International Journal of Obesity, 25, 940-948. http://dx.doi.org/10.1038/sj.ijo.0801635

Wallston, A., Wallston, S., \& De Vellis, R. (1978). Development of the Multidimensional Health Locus of Control (MHLC) Scales. Health Education \& Behavior, 6, 160-170. http://dx.doi.org/10.1177/109019817800600107

Watkins, J. A., Christie, C., \& Chally, P. (2008). Relationship between Body Image and Body Mass Index in College Men. Journal of American College Health, 57, 95-100. http://dx.doi.org/10.3200/JACH.57.1.95-100

Weiss, R., O’Loughlin, L., Platt, W., \& Paradis, G. (2007). Five-Year Predictors of Physical Activity Decline among Adults in Low-Income Communities: A Prospective Study. International Society of Behavioral Nutrition and Physical Activity, 4, 23. http://dx.doi.org/10.1186/1479-5868-4-23

Whitmer, A., Gunderson, P., Barrett-Connor, E., Quesenberry, P., \& Yaffe, K. (2005). Obesity in Middle Age and Future Risk of Dementia: A 27 Year Longitudinal Population Based Study. BMJ, 330, 1360. http://dx.doi.org/10.1136/bmj.38446.466238.e0

Wijk, C. (2011). Mood States Are Not Associated with BMI in Mentally Healthy Adults. Psychology, 2, $492-496$. http://dx.doi.org/10.4236/psych.2011.25076

Wirfalt, E., \& Jeffery, R. (1998). Using Cluster Analysis to Examine Dietary Patterns: Nutrient Intakes, Gender, and Weight Status Differ across Food Pattern Clusters. Journal of the American Dietetic Association, 97, 272-279. http://dx.doi.org/10.1016/S0002-8223(97)00071-0 